\title{
P02.99. Acupuncture combined with an antidepressant has a better effect on major depression: a multi-center, randomized, controlled clinical trial
}

\author{
T Guo*, Y Wang, L Sun, W Zhang, W Ma \\ From International Research Congress on Integrative Medicine and Health 2012 \\ Portland, Oregon, USA. 15-18 May 2012
}

\section{Purpose}

This study investigated whether the combination of acupuncture and the antidepressant medicine paroxetine has a better curative effect than paroxetine only for major depression (MD) in a multi-center, randomized, controlled clinical trial.

\section{Methods}

72 inpatients and outpatients with MD, diagnosed by the ICD-10, were randomly divided into three groups with three different treatments: combination of manualacupuncture and paroxetine (23 cases); combination of electro-acupuncture and paroxetine (32 cases); and paroxetine only (17 cases) for 6 weeks. Two statistical analyzing methods, intention to treat (ITT) and per protocol (PP), were applied to assess the main curative indexes, including Hamilton Depression Scale (HAMD), Self-rating depression scale (SDS), and Rating Scale for Side Effects (SERS) scores.

\section{Results}

Numbers of patients dropping out during the treatment were 3,5 , and 1 in the three groups. Patients in the two acupuncture groups got a more remarkable reduction in HAMD and SDS scores compared with those in the medicine only group, especially in the somatic factor scores. No significant differences were found between the two acupuncture groups ( $p>0.05)$. SERS scores in the $2^{\text {nd }}, 4^{\text {th }}$ and $6^{\text {th }}$ week showed significant differences among the three groups $(\mathrm{p}<0.05)$.

Beijing University of Traditional Chinese Medicine, Beijing, China

\section{Conclusion}

The findings indicate that the combination of acupuncture and antidepressant is superior to the antidepressant treatment only in term of improving patients' depressive symptoms, especially somatic symptoms. Acupuncture combined with antidepressant medicine can substantially improve patients' subjective feelings for quality of life. Acupuncture plays an important role in reducing the side effects caused by the antidepressant medicine and enhancing its curative effects.

Published: 12 June 2012

doi:10.1186/1472-6882-12-S1-P155

Cite this article as: Guo et al:: P02.99. Acupuncture combined with an antidepressant has a better effect on major depression: a multi-center, randomized, controlled clinical trial. BMC Complementary and Alternative Medicine 2012 12(Suppl 1):P155.

Submit your next manuscript to BioMed Central and take full advantage of:

- Convenient online submission

- Thorough peer review

- No space constraints or color figure charges

- Immediate publication on acceptance

- Inclusion in PubMed, CAS, Scopus and Google Scholar

- Research which is freely available for redistribution 